\title{
Evaluation of Liver Functions in Beta-thalassemic Patients in Ismailia
}

\author{
Marwa A. Ibrahim ${ }^{1^{*}}$, Ahmed Atef', Alaa E. Zeitoun', Hala El-Hagrasi', \\ Fadia M. Attia ${ }^{2}$
}

Departments of ${ }^{1}$ Pediatrics and ${ }^{2}$ Clinical Pathology, Faculty of Medicine, Suez Canal University, Egypt.

\begin{abstract}
Background and objective: Regular packed RBCs transfusion puts Beta-thalassemia major patients at a high risk of developing hepatic iron overload and hepatitis $C$ viral infection. Aim: The aim of this study was to evaluate liver functions in thalassemic patients in Ismailia. A descriptive cross sectional study was carried out in the outpatient pediatric hematological clinic of Suez Canal University hospital. Material and Methods: A sample of 25 Egyptian transfusion dependant $\beta$ thalassemia major children was studied. Individual patients underwent full history undertaking, clinical examination and a panel of laboratory tests including hemoglobin level, alanine aminotransferase (ALT), aspartate aminotransferase (AST), serum ferritin, hepatitis B surface antigen (HBs Ag) and hepatitis C virus antibody (HCV Ab). Results: Both ALT and AST means were elevated being $62.32 \mathrm{IU} / \mathrm{L}$ and $70.76 \mathrm{IU} / \mathrm{L}$ respectively. $32 \%$ of the studied patients were $\mathrm{HCV}$ Ab positive while no one was HBs Ag positive. A highly significant correlation between ALT and AST was found. There was a statistically significant relationship between serum ferritin and HCV Ab status. Conclusion: These findings suggest that both HCV and iron overload are the main causes of abnormal liver function in patients with thalassemia. The treatment of both problems if coexisting in patients with thalassemia is required to prevent progression to chronic liver diseases.
\end{abstract}

Keywords: hepatitis C, aminotransferase, transfusion, iron overload

\section{Introduction}

The thalassemia syndromes are a heterogeneous group of inherited anemias characterized by defects in the synthesis of one or more of the globin chain subunits of the adult hemoglobin tetramer ${ }^{(1)}$. Transfusion therapy, which is the mainstay of treatment, allows for normal growth and development and suppresses ineffective erythropoiesis. Iron overload results from both transfusional hemosiderosis and excess gastrointestinal iron absorption. Iron deposition in the heart, liver, and multiple endocrine glands results in severe damage to these organs, with variable endocrine organ failure ${ }^{(2)}$. In particular, beta-thalassemia major has a high mortality rate if regular red blood cell transfusions are carried out, but no chelation therapy is available ${ }^{(3)}$.

Transfusion-transmitted infections continue to be a major challenge for blood transfusion organizations across the world. The problem is more serious in the developing countries with lower economic means. Studies demonstrated that HCV is the most prevalent transfusion transmitted infection and remains a major health problem for these patients ${ }^{(4)}$. HCV is a major cause of chronic hepatitis in patients with thalassemia major and is associated with raised AST 
activity and serum ferritin concentration compared with patients seronegative for anti-HCV(5). The aim of this study was to evaluate liver functions in thalassemic patients in Ismailia.

\section{Materials and Methods}

In a descriptive cross sectional study, 25 beta thalassemia major patients aged from 5-18 years old were selected from the outpatient hematology clinic at Suez Canal University hospital in Ismailia, Egypt. Patients were selected based on a previous documented investigation for thalassemia by hemoglobin electrophoresis. The Ethics Committee of the Faculty of Medicine, Suez Canal University, approved the project and all patient guardians signed the consent form.

All patients had to be on a regular blood transfusion program. Cases of other known co-morbid diseases were excluded from this study. All patients underwent completed history taking and the focus was on the following parameters of interest: age at diagnosis, age at start of regular transfusions, inter-transfusion interval, the use of different chelating agents and history of splenectomy. Hematological investigations included: complete blood count (CBC), measurement of ALT, AST and serum ferritin levels. For comparisons, we considered values of ALT and AST as an index based upon 45IU/l, classifying patients as normal $(\leq 45 \mathrm{IU} / \mathrm{I})$ or as elevated ( $>45 \mathrm{IU} / \mathrm{I})$. HCV Ab and $\mathrm{HBs}$ Ag were detected in serum samples by a third generation enzyme-linked immune-sorbent assay.

\section{Statistical analysis}

Data were presented in the form of mean, range, percentage, and standard deviation as descriptive statistics. Descriptive statistics and statistical comparisons were per- formed using the statistical software program SPSS (version 13). Results were considered significant if $\mathrm{P}$-value was less than 0.05 .

\section{Results}

The study included 9 males and 16 females in the age range of 5-18 years (mean 10.56 \pm 3.96 ). All 25 patients had confirmed beta-thalassemia major diagnoses through analysis of $\mathrm{CBC}$ and hemoglobin electrophoresis. Clinical and laboratory parameters of the study population are summarized in tables 1 and 2 .

Table 1: Clinical parameters of the study population

\begin{tabular}{|l|cc|}
\hline Parameter & No. & $\%$ \\
\hline Frequency of blood & & \\
transfusion: & 16 & 64 \\
- Every 1 month & 9 & 36 \\
- Every 2 months & & \\
Splenectomy & 12 & 48 \\
Desferroxamine use & 16 & 64 \\
Oral chelating agents & 7 & 28 \\
\hline
\end{tabular}

Sixty-four percent of the studied thalassemic patients use Desferroxamine while only $28 \%$ use oral chelating agents, $64 \%$ have frequent blood transfusion every month and splenectomy was performed to $48 \%$ of them. Among the studied thalassemic patients, $48 \%$ had elevated ALT while $80 \%$ had elevated AST.

$\mathrm{HCV} A b$ was positive in $32 \%$ of the patients while no one was HBsAg positive. Serum ferritin level was elevated in $60 \%$. Serum ALT, AST and ferritin became elevated with the older the age of the thalassemics and earlier age of diagnosis and there was a highly statistically significant relationship between serum ferritin and the frequency of blood transfusion 
Table 2: Different laboratory parameters of the study population

\begin{tabular}{|l|l|}
\hline Parameter & No. (\%) \\
\hline ALT & \\
- Elevated (>45 IU/I) & $12(48 \%)$ \\
- Range & $62 \pm 44$ \\
& $17-167$ \\
AST & \\
- Elevated (>45 IU/I) & $20(80 \%)$ \\
- Mean \pm SD & $70 \pm 38$ \\
- Range & $19-173$ \\
Ferritin & \\
- Elevated ( $\geq 1000 \mu g / I)$ & $15(60 \%)$ \\
- Mean \pm SD & $2016 \pm 2094$ \\
- Range & $280-8318$ \\
HCV Ab (Positive) & $8(32 \%)$ \\
HBs Ag (Positive) & 0 \\
\hline
\end{tabular}

There was a significant relationship between serum ferritin and use of Desferroxamine, also there was a statistically significant relationship found between serum ferritin and HCV Ab status where serum ferritin was found elevated in HCV Ab positive With the irregular use of Desferroxamine ALT, AST and serum ferritin became elevated with their means being $92.8 \mathrm{IU} / \mathrm{l}, 76.1 \mathrm{IU} / \mathrm{l}$ and $3753.3 \mathrm{\mu g} / \mathrm{l} \mathrm{re-}$ spectively, and with increasing the dura- tion of Desferrxamine use both ALT and AST got elevated while serum ferritin and hemoglobin decreased with a statistically significant relationship between the duration of Desferroxamine use and AST level. While with oral chelating agents use ALT and AST became more elevated with their means being $64 \mathrm{IU} / \mathrm{I}$ and $73 \mathrm{IU} / \mathrm{I}$ respectively and serum ferritin being decreased $1520 \mu \mathrm{g} / \mathrm{l}$.

A statistically significant relationship between the duration of oral chelating agents use and level of ALT and AST was found. ALT, AST and hemoglobin means became elevated with splenectomy as shown in table (3). There was a highly significant correlation between ALT and AST, and as serum ferritin increases, ALT increases. HCV Ab positive patients had elevated ALT and AST with mean being 77.9lU/I and 72.0lU/I respectively. Also, it was found that $\mathrm{HCV} A b$ positive thalassemic patients had higher age mean, earlier age of diagnosis and shorter period of Desferroxamine and oral chelating agents use. HCV Ab positive patients had significantly elevated serum ferritin with mean being 3649.1 $\mathrm{g} / \mathrm{l} \quad(p=0.044)$.

Table 3: Comparison between the different laboratory parameters and Splenectomy

\begin{tabular}{|c|c|c|c|c|}
\hline \multirow[b]{2}{*}{ Parameters } & \multicolumn{2}{|c|}{ Splenectomy } & \multirow{2}{*}{$\begin{array}{l}\text { MW } \\
\text { Test }\end{array}$} & \multirow[t]{2}{*}{ P-value } \\
\hline & $\begin{array}{c}\text { Yes } \\
(\mathrm{N}=12)\end{array}$ & $\begin{array}{c}\text { No } \\
(\mathrm{N}=13)\end{array}$ & & \\
\hline ALT (IU/I) & $82 \pm 49$ & $44 \pm 30$ & 1.959 & $0.050^{*}$ \\
\hline AST (IU/I) & $88 \pm 43$ & $54 \pm 25$ & 2.340 & $0.019 *$ \\
\hline Ferritin $(\mu \mathrm{g} / \mathrm{l})$ & $1738 \pm 1205$ & $2273 \pm 2700$ & 0.082 & 0.935 \\
\hline $\mathrm{HB}(\mathrm{g} / \mathrm{dl})$ & $7.2 \pm 1.2$ & $7.0 \pm 2.5$ & 0.517 & 0.605 \\
\hline
\end{tabular}

* Statistically-significance

\section{Discussion}

Liver functions have been evaluated through the evaluation of the plasma levels of ALT and AST, as they leak into the plasma in case of liver injury and can be useful for its diagnosis and monitoring. It was found that $48 \%$ of the studied thalassemic patients had elevated ALT with ALT mean being $62.32 \mathrm{IU} / \mathrm{l}$ while $80 \%$ had elevated AST with AST mean being $70.76 \mathrm{IU} / \mathrm{l}$ and these results are similar to those obtained by Prati D. et $\mathrm{al}^{(6)}$; where 
$70 \%$ of the studied thalassemic patients had abnormal aminotransferase concentrations $^{(6)}$.

Sixty percent of the studied thalassemics had elevated serum ferritin (mean $2016 \mu \mathrm{g} / \mathrm{l}$ ) because of regular packed RBCs transfusions. All $\beta$-thalassemia patients had abnormally very high levels of serum ferritin $(2397 \mu \mathrm{g} / \mathrm{l})$ compared to reference range $(7-140 \mu g / l)$, indicating these patients have iron overload, probably due to multiple packed RBCs transfusion, increased dietary iron absorption or inadequate chelating therapy ${ }^{(7)}$. The prevalence of anti-HCV Ab among the thalassemic patients in the study was found to be 8 out of 25 patients (32\%), while no one was hepatitis $B$ surface antigen positive. The prevalence of Hepatitis $B$ and $C$ viral infection varies worldwide where Wanachiwanawin et al. $^{(8)}$ performed a study among 104 of the thalassemic patients where 21 (20.2\%) tested positively by enzyme immunoassay for anti-HCV antibody, whereas only 2 patients (2\%) had the hepatitis B surface antigen. Packed RBCs transfusions are safe in developed countries, since the introduction of blood donor screening for HBV and HCV infection, the residual risk has essentially been limited to blood units collected during the "window period", the period between the time of infection and the time when antibodies against the virus $C$ are detectable in the serum. To minimize even this residual risk, some national health organizations have added determination of HBVDNA and HCV-RNA by nucleic acid technology to the battery of screening tests ${ }^{(9)}$.

Vaccination against HBV infection is a key intervention in preventing the transmission of HBV and is a critical strategy in reducing the global morbidity and mortality ${ }^{(10)}$. In this study there was a highly statistically significant relationship between serum ferritin and the frequency of packed RBCs transfusion, as regular transfusion therapy leads to iron overloadrelated complications including liver fibrosis and cirrhosis ${ }^{(11)}$. Also a statistically significant relationship found between serum ferritin and HCV Ab status where serum ferritin was found elevated in HCV $\mathrm{Ab}$ positive patients.

In the present study, it was found that with the irregular use of Desferroxamine ALT, AST, and serum ferritin became elevated with their means being $92.81 \mathrm{U} / \mathrm{l}$, $76.1 \mathrm{IU} / \mathrm{I}$ and $3753.3 \mu \mathrm{g} / \mathrm{l}$ respectively. This is because chronic iron overload due to blood transfusions leads to significant morbidity and early mortality unless adequate chelation therapy is administered. Desferroxamine is the reference chelation therapy, but compliance to the treatment is often poor because it must be administered by prolonged subcutaneous or intravenous infusion $^{(12)}$. Long-term treatment with Desferroxamine has been shown to slow the accumulation of excess iron in the liver and can slow or eliminate the progression of a serious form of liver damage as liver fibrosis.

A statistically significant relationship between AST and splenectomy was found where AST mean was markedly elevated with splenectomy as post splenectomy the patients is more liable to infections by various organisms that may involve the liver resulting in elevation of liver enzymes ALT and AST, also following splenectomy progressive hepatic enlargement occur reflecting the trapping of abnormal thalassemic cells in a large hepatic pool causing engorgement and hypertrophy and may also reflect intensive extramedullary erythropoiesis ${ }^{(13)}$. There was a highly significant correlation between ALT and AST. Also it was found that as serum ferritin increases, ALT increases,and this agrees with Ameli et al. ${ }^{(14)}$ who found that the mean serum ferritin was signifi- 
cantly higher in patients with ALT > or $=40$ $(2553 \mu \mathrm{g} / \mathrm{L}$ versus $1783 \mu \mathrm{g} / \mathrm{L})(\mathrm{p}=0.012)$. In the present study, we found that HCV Ab positive patients had elevated ALT and AST with mean being $77.9 \mathrm{IU} / \mathrm{l}$ and 72.0 IU/I respectively. This agrees with Ameli $M$. et $\mathrm{al}^{(14)}$ who found a significant relationship between elevated ALT and anti HCV positivity. Also Chang et al $^{(15)}$ showed that the prevalence of raised ALT and AST ( $\geq 45 \mathrm{IU} /$ liter) in the HCV Ab positive group was more significant than in the negative group.

HCV Ab-positive patients have significantly elevated serum ferritin (mean $3649.1 \mu \mathrm{g} / \mathrm{l})(\mathrm{p}=0.044)$ and this agrees with Gattoni et al. ${ }^{(16)}$ showing that patients with elevated serum iron markers have more chronic hepatitis. This can be explained by the fact that serum ferritin is considered as an acute phase reactant that may increase in the presence of viral hepatitis. It is concluded that HCV is a major cause of chronic hepatitis in patients with thalassemia major and is associated with raised ALT activity, serum ferritin concentration, and transfusion index compared to patients seronegative for anti-HCV.These findings suggest that both $\mathrm{HCV}$ and iron overload are the main causes of abnormal liver function in patients with thalassemia. Treatment of both problems is required to prevent progression to chronic liver disease. We recommended reevaluating transfusion and Desferroxamine doses and therapies other than blood trans-fusion in these patients.

\section{References}

1. Goldman L, Dennis A: Cecil textbook of medicine, 22nd edition. Saunders 2004; 168:913-1011.

2. Rund $D$ and Rachmilewitz : $\beta$-thalassemia. N Engl J Med 2005; 353: 1135-46.
3. Kontoghiorghes GJ. Advances in oral iron chelation in man. Int J Hematol 1992; 55:2738.

4. Rezvan H, Abolghassemi H, Kafiabad SA. Transfusion-transmitted infections among multitransfused patients in Iran: a review. Transfus Med. 2007 Dec; 17(6):425-33.

5. Wonke B, Hoffbrand AV, Brown D, Dusheiko G. Antibody to hepatitis $C$ virus in multiply transfused patients with thalassemia major. J Clin Pathol 1990; 43:638-40.

6. Prati $D$, Maggioni $M$, Milani S, Cerino $M$, Cianciulli P, Coggi G, et al. Clinical and histological characterization of liver disease in patients with transfusion-dependent betathalassemia. A multicenter study of 117 cases. Haematologica 2004; 89:1179-86.

7. Kamal M.,Talal A. Lipid profile in Jordian children with $\beta$-thalassemia major. UHOD 2008; 18:93-8.

8. Wanachiwanawin W, Luengrojanakul P, Sirangkapracha P, Leowattana W, Fucharoen S.Prevalence and clinical significance of hepatitis $C$ virus infection in Thai patients with thalassemia. Int J Hematol. 2003; 78(4):374-8.

9. Hankins JS, Smeltzer MP, McCarville MB, et al. Patterns of liver iron accumulation in patients with sickle cell disease and thalassemia with iron overload. Eur J Haematol. 2010; 85(1):51-7.

10. Di Marco V., Capra M., Angelucci E.,et al. Management of chronic viral hepatitis in patients with thalassemia: recommendations from an international panel. Blood, 2010; 116(16)2875-83.

11. Galanelloa R.and Origaa R. Betathalassemia. Orphanet J Rare Dis. 2010; 5: 11.

12. Vermylen C.What is new in iron overload?. Eur J Pediatr 2008; 167:377-81.

13. Higgs DR, Thein SL, Woods WG. The molecular pathology of the thalassemia. In: Weatherall DJ, Clegg B, editors. The thalassemia syndromes $.4^{\text {th }}$ ed. Oxford (UK): Blackwell Science 2001; 133-91.

14. Ameli M, Besharati S, Nemati K, Zamani F. Relationship between elevated liver enzyme with iron overload and viral hepatitis in thalassemia major patients in Northern Iran. Saudi Med J. 2008 Nov; 29(11):1611-5. 
15. Chang CJ, Ko Yc, Liu HW. Serum alanine aminotransferase levels in relation to hepatitis $B$ and $C$ virus infections among drug abusers in an area hyperendemic for hepatitis B. Dig Dis Sci 2000;45:1949-52.
16. Gattoni A, Parlato A, Vangicri B, Bresciani $M$, Derna R, Baldassarre R. Role of hemochromatosis genes in chronic hepatitis $C$. Clin Ter 2006;1571:61-8 